\title{
A comparison of paraffin and resin-based techniques used in bark anatomy
}

\author{
Thomas Hamann, ${ }^{1}$ Erik Smets ${ }^{1,2}$ \& Frederic Lens ${ }^{1,2}$ \\ 1 Netherlands Centre for Biodiversity Naturalis (section NHN) - Leiden University, P.O. Box 9514, 2300 RA Leiden, The Netherlands \\ 2 Laboratory of Plant Systematics, Institute of Botany and Microbiology, Kasteelpark Arenberg 31 Box 2437, K.U. Leuven, \\ 3001 Leuven, Belgium \\ Author for correspondence: Thomas Hamann,hamann@nhn.leidenuniv.nl
}

\begin{abstract}
Bark anatomy is an unappreciated discipline in plant systematics, despite its great potential to reveal systematically informative features. In this paper, main reasons for the lack of detailed bark anatomical data in many plant families are identified, including problems with sectioning, terminological issues, and difficulties in observation of dilated stems. We deal with these problems by focusing on two aspects: (1) compare, discuss and improve existing sectioning and maceration techniques using two species with soft and hard bark tissues; and (2) discuss the best way to collect stem bark samples. We hope that this paper will stimulate inclusion of bark anatomical data in future systematic studies.
\end{abstract}

Keywords bark anatomy; light microscopy; macerations; plant systematics; phloem; sectioning

Supplementary Material Score sheet and a filled-out example of Davidia involucrata are available in the Electronic Supplement to the online version of this article (http://www.ingentaconnect.com/content/iapt/tax).

\section{INTRODUCTION}

Although bark is one of the most conspicuous features of woody plants in the field, and despite several studies having shown its potential for improving phylogenetic relationships in many plant families (e.g., Metcalfe \& Chalk, 1950a, b; Zahur, 1959; Esau, 1969; Richter, 1981; Roth, 1981; Esau \& Cheadle, 1984; Archer \& Van Wyk, 1993; Liu \& Gao, 1993; Costa \& al., 1997; Carlquist, 1991, 1996, 1998, 2005; De Magistris \& Castro, 2001; Castro \& al., 2005; Olson, 2005; Schweingruber, 2006; Junikka \& Koek-Noorman, 2007; Oskolski \& al., 2007, 2010), bark is still one of the most poorly known plant tissues and therefore rarely included in systematic studies. There are three major reasons for the fragmentary knowledge of bark anatomical data. Firstly, bark often has a combination of soft parenchymatous tissues and very thick-walled cells, making thin $(10-15 \mu \mathrm{m})$ high-quality sections problematic and causing the sections to be easily damaged during the treatment procedure afterwards. Different types of embedding techniques have been used to overcome this problem (e.g., celloidin, Johansen, 1940; polyethyleneglycol (PEG), Richter, 1981; paraffin, Carlquist, 1982; freezing microtome sections, cf. Ruzin, 1999; resin, Melzer \& al., 2008; polystyrene foam, Barbosa \& al., 2010), but obtaining good bark sections often remains difficult. Secondly, many bark anatomical papers were published before the standardized-terminology paper of Trockenbrodt (1990), and consequently they lack a unified terminological framework, which can lead to interpretation issues and makes comparisons difficult (see also Esau, 1969; Trockenbrodt, 1990). Despite useful additions to Trockenbrodt's paper by Ley-Yadun (1991) and Junikka (1994), a standardized explanatory list similar to the "IAWA List of Microscopic Features for Hardwood Identification" (IAWA Committee, 1989) has never been published. Thirdly, many bark anatomical studies lack crucial information on potentially informative characters, such as the position of the initiation of the periderm. Furthermore, information on how bark tissue changes over time is commonly missing: dilatation events, development of (fiber)sclereids, and rhytidome formation can cause dramatic changes to the original position of particular cells in the bark, which again can lead to incorrect interpretations.

This article was written because we encountered all of the problems mentioned above during the first author's M.Sc. thesis work (Hamann, 2009). However, by adding minor but crucial adjustments to the ethylenediamine protocol of Carlquist (1982) using species having soft as well as hard tissues in their bark, we managed to obtain better bark anatomical sections as compared to the original Carlquist method. In this paper we discuss how to (1) collect stems prior to sectioning, and (2) facilitate the making of high-quality thin bark sections for light microscopy using paraffin and resin embedding. We hope that this article will stimulate future bark anatomical research.

\section{MATERIALS AND METHODS}

How to collect bark specimens. - Generally, there are three possible sources of suitable specimens, in order of preference: (1) fresh material collected in the field, (2) existing fixed collections in alcohol or FAA, and (3) dried wood collections present in xylaria and herbaria. 
(1) When many species need to be collected, fieldwork can be time-consuming and expensive, but self-collecting has major advantages over existing collections made by others. The most important one is being able to carefully select suitable plants with sufficiently mature stems, which are free of diseases and/or physical damage. Furthermore, it is possible to sample stems of different diameters of the same plant, including shoot tips and young twigs, allowing observation of the ontogenetical variation of the various bark tissues due to dilatation and other development processes (e.g., position of phellogen initiation). A suitable saw (e.g., Gardena folding saw, Gardena, Ulm, Germany) can be used to carefully remove stem material from a living plant. It is also possible to use core increments to obtain samples from thick stems, but there is a risk of damaging the bark tissues when inserting and removing the cutting tube, or when removing the sample from the cutting tube (Forster \& al., 2000; Rossi \& al., 2006; Boura \& De Franceschi, 2008). If desired, tissues can be put immediately after collection in an appropriate fixative, such as Craff III, IV, or V for small and relatively soft samples and FAA for larger and harder samples (Sass, 1968), but this will not affect the quality of the sections. Evidently, each collected specimen should be accompanied by a label including the exact collection location and detailed ecological information. Photographs of the bark morphology in the field may be helpful too. Using this strategy, it is possible to discuss the impact of ecological parameters on bark structure, which remains an unexplored field in bark anatomy (compare vestured pits in xylem; Jansen \& al., 2004). Botanical gardens and greenhouses can be a viable alternative for collecting in the wild, but cultivars and unusually fast growing plants in greenhouses should be avoided (Lens \& al., 2008).

(2) Most stem material in alcohol collections only includes young twigs. However, when mature material is present, it is almost as suitable for bark anatomical studies as self-collected material. Depending on the age, material from alcohol collections faces a few issues, such as the hardening effect of alcohol, which may cause difficulties during sectioning, and dissolving of some cellular contents, especially pigments and lipids. Properly fixating material before storage in $70 \%$ alcohol may prevent some of these issues.

(3) In herbarium specimens and a considerable number of wood specimens stored in xylaria, the bark is still attached. Although hundreds of these samples can be easily collected in a short time, most of them will not be usable for high-quality bark anatomical observations due to drying and degradation of the soft tissues. This is especially the case in specimens collected more than ten years ago. Consequently, the fragile, non-lignified cell types collapse (e.g., sieve elements) and the bark may detach from the wood, resulting in destruction of the vascular cambium and adjacent cells. Moreover, the resulting sections may degrade further during the treatment process. An additional problem with herbarium samples is that the vast majority consists of juvenile branches with poorly developed bark. In general, mature, dried wood specimens not older than ten years that still have the bark firmly attached provide satisfactory bark sections.
Preparation for light microscopy. - Several steps are required to prepare slides suitable for detailed bark observations. We have used Carlquist's (1982) ethylenediamine softening and paraffin method, suggest some modifications for improvement, and compare it with a commonly used LR White hard grade resin-based technique (London Resin Company, London, U.K.; Tables 1-2; Figs. 2-3). Other resins like Epon (Hexion, Rotterdam, The Netherlands) or Technovit (Heraeus-Kulzer, Wehrheim, Germany) also work, but our experience has learned that LR White impregnates the tissues better.

Suggestions for refining the embedding process using Carlquist's (1982) protocol. - Carlquist's (1982) method consists of softening small bark tissue samples in 4\% ethylenediamine for three to four days, followed by rinsing in water, dehydration using alcohol and Johansen's tertiary butanol series (Johansen, 1940), and embedding in high-grade paraffin with a $59^{\circ} \mathrm{C}-61^{\circ} \mathrm{C}$ melting point. Because we could not obtain paraffin with this melting point, we used Peel-a-wax paraffin (Electron Microscopy Sciences, Hatfield, Pennsylvania, U.S.A.) with a $62^{\circ} \mathrm{C}-64^{\circ} \mathrm{C}$ melting point (paraffin with a melting point lower than $60^{\circ} \mathrm{C}$ should not be used). Suggestions for improvement are detailed in bold in Table 1. Although Carlquist (1982) recommends that the tissue samples should not be larger than $5 \times 5 \times 1 \mathrm{~mm}$, we have successfully embedded and sectioned tissue samples of $8 \times 8 \times 1 \mathrm{~mm}$ and also succulent stem segments up to $35 \times 10 \times 5 \mathrm{~mm}$. Generally, less-lignified samples can be larger than heavily lignified material, but they should never be larger than necessary to observe all informative characters. The different rinsing steps in water, alcohol, and tertiary butanol are notably improved during the embedding process by using a slowly moving orbital shaker (Ika-Vibrax-VXR, Janke \& Kunkel, Staufen, Germany) to keep the fluids moving. The paraffin infiltration is further improved by extending the time each rinsing step takes and by always exsiccating the paraffin before use. When embedding a tissue sample for tangential sections, it is placed in the mold with the wood part facing downwards to ensure no bark material is lost during sectioning. We have found that single-use peel-away plastic ice cube molds are perfect for molding small paraffin blocks. For larger blocks, molds may be made out of paper or aluminum foil (Echols, 1955; Sass, 1968). The embedded paraffin samples are first hardened at room temperature $\left(20^{\circ} \mathrm{C}\right)$ for one to several hours depending on size. Use of a cold plate (Adamas Instrumenten, Rhenen, The Netherlands) is suggested to accelerate the hardening. Then samples are transferred to a refrigerator and hardened further at low temperature $\left(0^{\circ} \mathrm{C}-5^{\circ} \mathrm{C}\right)$ for several days (Sass, 1968).

Sectioning, staining and mounting of paraffin embedded tissues. - Procedures for sectioning, slide preparation, staining, and mounting are detailed in Table 2. Before sectioning starts, the paraffin blocks are trimmed into a trapezium shape to make them suitable for use in a rotary microtome. A few sections are cut to expose the surface, and the blocks are placed face down in a dish with 2-3 $\mathrm{mm}$ of water in a refrigerator overnight (Carlquist, 1982). Transverse, tangential, and radial sections 5-10 $\mu \mathrm{m}$ thick are cut from their respective paraffin blocks using a rotary microtome (Leitz, Wetzlar, Germany). From each of the transverse and radial tissue blocks only about a dozen 
Table 1. Procedures for Carlquist's (1982) ethylenediamine method with our modifications in bold, and for LR White embedding.

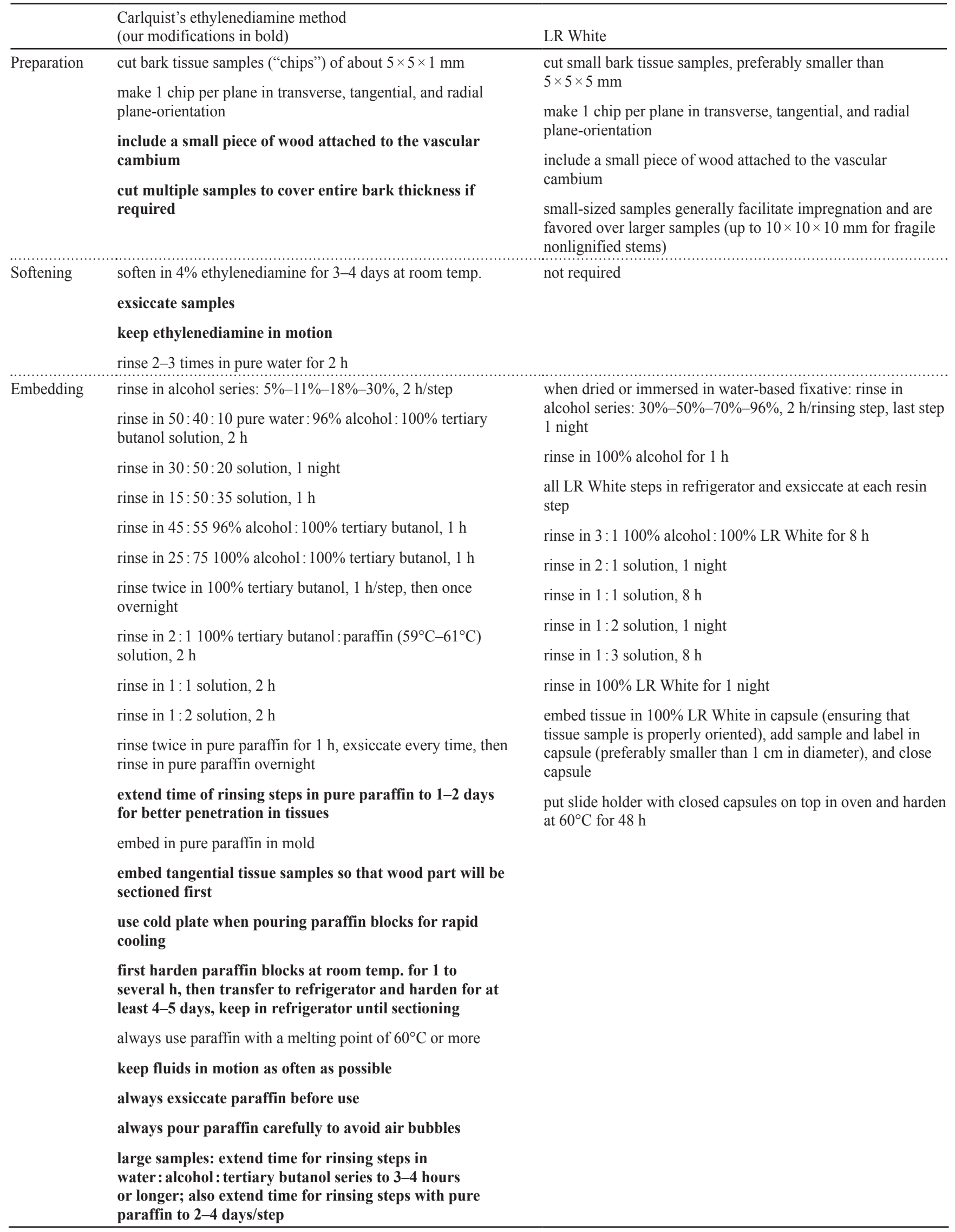


Table 2. Procedures for sectioning, mounting and staining for paraffin embedding and LR White hard-grade embedding.

\begin{tabular}{lll}
\hline & Paraffin embedding & LR White hard-grade embedding \\
\hline $\begin{array}{l}\text { Sectioning } \\
\text { and slide }\end{array}$ & trim paraffin blocks into trapezium shape for sectioning & $\begin{array}{l}\text { dissolve } 2 \mathrm{~g} \text { of gelatin in } 500 \mathrm{ml} \text { of water at } 50^{\circ} \mathrm{C}, \text { then add and } \\
\text { dissolve } 0.2 \mathrm{~g} \text { chromium(III) potassium sulfate }\end{array}$
\end{tabular}

preparation knife inclination: $1^{\circ}$

use extra-hard disposable microtome knives

make several sections until the surface of the bark sample is exposed, then place the paraffin block surface down in a dish with 1-2 $\mathrm{mm}$ of pure water, soak overnight in refrigerator

cut sections 5-10 $\mu \mathrm{m}$ thick

place sections in storage tray in same order as they were cut

place marked slides on a heating element at $40^{\circ} \mathrm{C}$ and cover them with Riopel's adhesive followed by a thin layer of pure water

place sections on slides in same order as they were cut

heat fix sections to slides at $40^{\circ} \mathrm{C}$ for at least $1 \mathrm{~h}$

Staining and

mounting

\section{Safranin/alcian blue}

rinse slides with sections three times in xylene, $5 \mathrm{~min}$

rinse in alcohol series: $100 \%-96 \%-70 \%-50 \%-30 \%, 2 \mathrm{~min} / \mathrm{step}$

rinse in pure water, $2 \mathrm{~min}$

stain in alcian blue/safranin $(2: 11 \%$ alcian blue in water : $1 \%$ safranin in ethanol 50\%), $20 \mathrm{~min}$

rinse twice in pure water, $2 \mathrm{~min}$

rinse in alcohol series: $30 \%-50 \%-70 \%-96 \%-100 \%, 2 \mathrm{~min} / \mathrm{step}$

rinse three times in xylene, $5 \mathrm{~min} / \mathrm{step}$

mount sections in Depex resin, apply coverslip

dry slides for 4-7 days at room temp.

\section{Phloem stain according to Cheadle \& al. (1953)}

rinse slides with sections three times in xylene, $5 \mathrm{~min}$

rinse in alcohol series: $100 \%-96 \%-70 \%-50 \%-30 \%, 2 \mathrm{~min} / \mathrm{step}$

rinse in pure water, $2 \mathrm{~min}$

stain in $1 \%$ tannic acid, $5-10 \mathrm{~min}$

rinse three times in pure water, $2 \mathrm{~min}$

stain in $1 \%-2 \%$ iron chloride, 5 min

rinse three times in pure water, $2 \mathrm{~min}$

check if sufficiently stained

rinse in $1 \% \mathrm{NaHCO}_{3}$ in $25 \%$ alcohol, at least $30 \mathrm{~min}$

stain in saturated solution of lacmoid in $30 \%$ alcohol with a few milliliter of the $1 \% \mathrm{NaHCO}_{3}$ solution added for $18 \mathrm{~h}$ or longer, keep lacmoid solution in motion while staining

rinse in $1 \% \mathrm{NaHCO}_{3}$ in $50 \%$ alcohol, $20 \mathrm{~s}$

rinse in alcohol series: $70 \%-96 \%-100 \%, 2 \mathrm{~min} / \mathrm{step}$

rinse three times in xylene, $5 \mathrm{~min}$

mount sections in Depex resin, apply coverslip

dry slides for 4-7 days at room temp. dip slides in cooled chrome alum-gelatin adhesive, then dry for 1 night at $32^{\circ} \mathrm{C}$

use tungsten carbide D-knife, knife inclination: $5^{\circ}$ (glass knives also work)

trim block until desired region of tissue is reached cut sections $4-8 \mu \mathrm{m}$ thick

put $40 \%$ aceton to the slides, add sections and place on a heating element at $60^{\circ} \mathrm{C}$

heat fix sections to slides for $1 \mathrm{~h}$ at $60^{\circ} \mathrm{C}-70^{\circ} \mathrm{C}$

\section{Toluidine blue}

stain sections on slides in $1 \%$ toluidine blue for $20 \mathrm{~s}$

rinse slides once or twice in pure water for $2 \mathrm{~min}$ dry slides at room temp.

mount sections in Depex mounting medium and add cover slip dry slides for 4-7 days at room temp. 
sections need to be cut. However, serial sections covering the entire bark thickness should be cut from the tangential block. Extra-hard Feather N35 disposable microtome knives (Feather, Osaka, Japan) are used, with a knife inclination of $1^{\circ}$. The slides are covered with a thin layer of Riopel's adhesive (Riopel, 1962), followed by a thin layer of water on which the sections float. It is important to use as few Riopel's adhesive as possible on the slides to minimize staining of the adhesive later onwards. If a strong staining of the Riopel adhesive still occurs, it is also possible to use the subbed slides used for LR White sections, but the sections are much more likely to fall off the slides during the staining process. The tangential sections on each slide should be arranged in the same order as they were sectioned; subsequent (strips of) sections are placed on numbered slides. Staining of all sections occurs using two different stains: (1) safranin/alcian blue stain which is a standard double stain for wood (Lens $\&$ al., 2005, 2007; even numbered slides) and (2) the phloem stain (Cheadle \& al., 1953; odd numbered slides). Other stains that can be used are acridin red-chrysoidin (Junikka \& KoekNoorman, 2007) or cresyl-violet (Keating, 1996). To improve the staining of callose by the lacmoid solution, the containers are kept in motion during the entire 18 hour period by placing them on a slowly moving orbital shaker. Finally, the sections are mounted in Depex mounting medium (VWR International, Amsterdam, The Netherlands). The excess Depex mounting medium can be removed from the slides using a razor blade after 4-7 days of drying in a fume hood. Then a voucher label listing species name, collector name and number, collection location, type of section, and slide number is glued to each slide using bookbinder glue.

LR White method. - The procedure for embedding, sectioning, staining and mounting tissues embedded in LR White resin is detailed in Tables 1 and 2. Properly orienting the tissue samples in the capsules is crucial, as corrections of obliquely orientated samples during sectioning are limited. Before sectioning, LR White blocks can be trimmed in a trapezium shape using a trimming device (Dremel Europe, Breda, The Netherlands) to remove superfluous LR White (dust is carcinogenic - wear respiratory protection). To improve the adhesion of the sections, the slides are subbed with chrome alum-gelatin adhesive (Appelhans, pers. comm.; based on Pappas, 1971) and left to dry at $60^{\circ} \mathrm{C}$ for 1 night before use. All sections were cut using a Microm HM360 automatic rotary microtome (Thermo Fisher Scientific, Walldorf, Germany), using a tungsten carbide D-knife, with a knife angle of $5^{\circ}$ and a section thickness of 4-8 $\mu \mathrm{m}$. The sections can be stained with toluidine blue (1 $\mathrm{g}$ sodium tetraborat (Borax) and $1 \mathrm{~g}$ toluidine in $100 \mathrm{ml}$ pure water) (Mercer, 1963; Burns, 1978) or safranin (but not with alcian blue or lacmoid, which cannot penetrate LR White resin).

Bark samples and techniques used. - Fresh bark material of Impatiens niamniamensis Gilg (Ericales, Balsaminaceae) was obtained from the living collections of the National Botanic Garden of Belgium (accession number 19770093), while fresh bark material of Davidia involucrata Baill. (Cornales, Nyssaceae) was retrieved from the living collections of the Hortus Botanicus Leiden (accession number A95059). The two species were selected based on their bark structure: I. niamniamensis is characterized by a soft, semisucculent stem without thickwalled sclerified cells, while the bark of $D$. involucrata contains large zones of very thick-walled sclereids. To show the difference between dried and fresh material, some samples of both species were dried at $60^{\circ} \mathrm{C}$ for five days in an oven. Fresh and dried material of both species was treated using both Carlquist's (1982) ethylenediamine protocol and our adjusted method, and according to the LR White hard-grade technique. Sections were cut, stained, and mounted using the methods described above, and pictures were taken with a Colorview IIIu digital camera connected to a $\mathrm{PC}$ running Cell ${ }^{\wedge} \mathrm{D}$ imaging software, attached to a Olympus BX-51 microscope (Olympus Nederland B.V., Zoeterwoude, The Netherlands).

To illustrate the advantages of each stain, fresh material of Rhododendron ponticum (Ericales, Ericaceae), a species that has very narrow sieve elements with very small sieve plates, was obtained from the Bos van Bosman park in Leiden and embedded using our improved paraffin method.

Macerations. - Fresh material of Davidia involucrata from the Hortus Botanicus Leiden (accession number A95059) was compared with 40-year-old dried material of the same species obtained from the NHN-L xylarium (Basel, Bot. Gart. 130/H, Lw 0708156). Fresh and dried bark slivers of D. involucrata were macerated using different protocols: (1) Jeffrey's maceration fluid (cf. Johansen, 1940; Table 3), (2) Franklin's

Table 3. Summary of maceration procedure according to Jeffrey's method (Johansen, 1940) with our improvements in bold.

\begin{tabular}{ll}
\hline Preparation & divide bark into slivers thinner than $300 \mu \mathrm{m}$ \\
& put slivers in numbered vials filled with pure water and exsiccate to remove all air \\
$\begin{array}{l}\text { Maceration and } \\
\text { rinsing }\end{array}$ & macerate slivers in Jeffrey's maceration fluid at room temp., 24 $\mathrm{h}$ \\
& centrifuge material for $3-5 \mathrm{~min}$, rinse with pure water by centrifuging material for $3-5$ min to remove all traces of maceration \\
& fluid (repeat until water is clear) \\
$\begin{array}{l}\text { Staining and } \\
\text { mounting }\end{array}$ & stain with astra blue (0.5 g astra blue and $\mathbf{2} \mathbf{g}$ tartaric acid in $\mathbf{1 0 0} \mathbf{m l}$ of pure water) at room temp., 1 night \\
& put a few drops of glycerin-gelatin on a slide on a heating element, then place some macerated tissue on slide \\
& carefully tease tissue apart with dissection needles and swirl around until evenly spread on slide \\
& place cover slip \\
& let glycerin-gelatin solidify at room temp.
\end{tabular}


wood maceration fluid (Franklin, 1945), (3) Gifford's fragile tissue maceration fluid (cf. Ruzin, 1999), (4) Mahlberg's parenchyma and collenchyma maceration fluid (cf. Ruzin, 1999), and (5) Schmid's improved Jeffrey's method (Schmid, 1982). For each rinsing step the material was centrifuged at $4000 \mathrm{rpm}$ for three to five minutes in pure water to avoid losing any macerated tissue and to speed up the process. Pipettes were used instead of decanting to further avoid loss of macerated material. Different staining methods were tried in combination with Jeffrey's original method: (1) astra blue in water (cf. Table 3), (2) 1\% safranin $\mathrm{O}$ in water and destaining in water (cf. Johansen, 1940), and (3) $1 \%$ safranin $\mathrm{O}$ in $50 \%$ alcohol preceded by dehydration (cf. Johansen, 1940). When making slides, the macerated tissue is carefully pulled apart using dissecting needles, and then swirled through the glycerin-gelatin, after which a cover slip is applied.

Observations. - To standardize our descriptions, we created a score sheet listing the characters as defined by Trockenbrodt (1990) and Junikka (1994). At the top of the score sheet, the observer writes down the specimen information, including stem diameter and number of growth rings, and voucher data. This is followed by a list of measurements of main bark anatomical tissues. Our score sheet, as well as a filled-out example of Davidia involucrata, is available in the Electronic Supplement on the Taxon website. A standardized description format is dependent on the group of study, however, and should not be used at a high taxonomic level. Consequently, observations that do not fit any of the pre-defined categories are written down separately on the score sheet, and categories may be marked as 'not applicable' if required.

\section{- RESULTS AND DISCUSSION}

Stains. - Safranin stains lignified cell walls red, as well as the cells' nucleus, while alcian blue colors cellulose in the nonlignified cell walls blue and also stains the cells' cytoplasmic details (Fig. 1A). Due to this specific double staining the various cell types and cellular features are simple to recognize. However, sieve plates and lateral-wall sieve areas are very hard to distinguish in this species with very narrow sieve elements (arrows in Fig. 1A). The phloem stain by Cheadle \& al. (1953) colors cellulose walls, cytoplasm, P-proteins, and nuclei light brown to grayish brown, while callose and lignified cellulose are clear blue to greenish-blue (Fig. 1B). So, using the Cheadle $\&$ al. stain, sieve plates and lateral-wall sieve areas are more easily recognizable due to their distinctive blue color, but other cellular features are more difficult to observe than with the safranin/alcian blue stain. The two stains used are complimentary, and allow better observation of cellular features and contents than using only one type of stain.

Embedding. - In this paper, we suggest several adjustments to Carlquist's (1982) protocol for paraffin embedding that improve the section quality of bark using model species with (1) soft bark cells without sclerified cell walls (Impatiens niamniamensis; Fig. 2) and (2) a heterogenous combination of soft and hard bark tissues (Davidia involucrata; Fig. 3). The most important adjustments are to (1) keep the fluids in motion during embedding and staining, (2) exsiccate the paraffin during embedding, (3) extend rinsing times for better penetration of the tissues, (4) use a slide adhesive that minimizes the risk of loosing sections after mounting, and (5) use extra-hard disposable microtome knives during sectioning. It is evident that fresh samples (Figs. 2B, D, F, 3B, D, F) yield much better sections than dried samples (Figs. 2A, C, E, 3A, C, E) when using the same technique. In dried Impatiens samples the secondary phloem cells are usually crushed, and the dilatated cortex cells often damaged, while in Davidia the axial and ray parenchyma cells, and to a lesser degree the sieve elements often collapse. When dried samples are investigated, bark tissues embedded in paraffin (Fig. 2A, C, 3A, C) generate much better quality sections than LR White-embedded tissue (Figs. 2E, 3E). Probably, this not only relates to the rehydration of the paraffin blocks
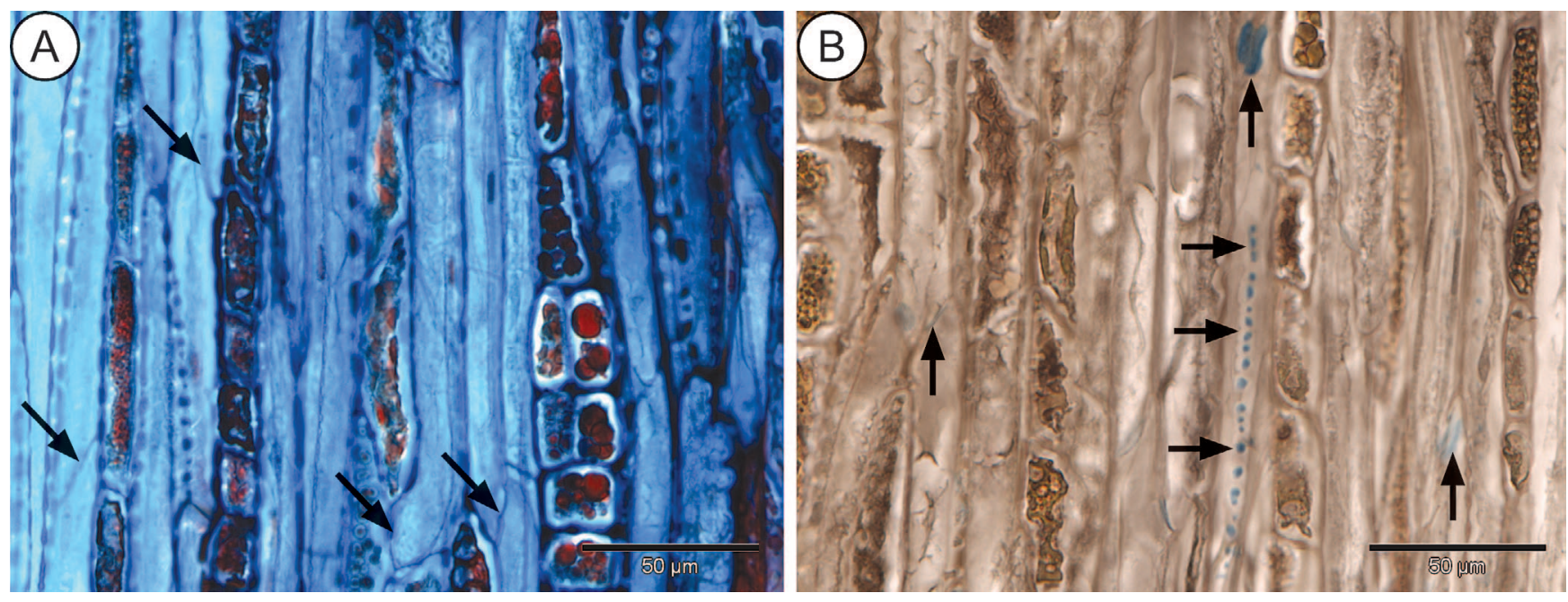

Fig. 1. Light microscope pictures of tangential bark sections of Rhododendron ponticum. A, Safranin/alcian blue stain; sieve plates and lateral sieve areas are difficult to distinguish (arrows). B, Stain according to Cheadle \& al. (1953) colors sieve plates (vertical arrows) and lateral sieve areas (horizontal arrows) blue. 


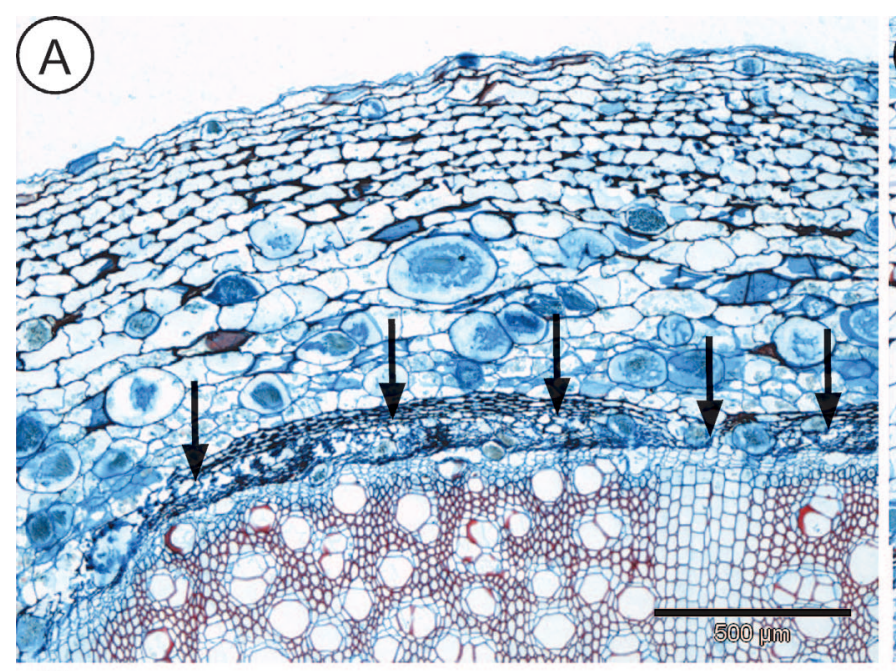

(C)

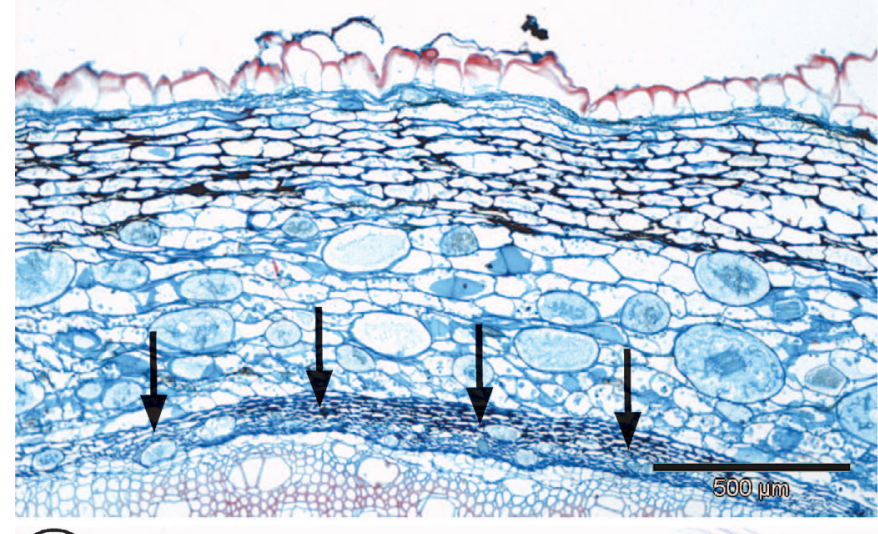

(E)

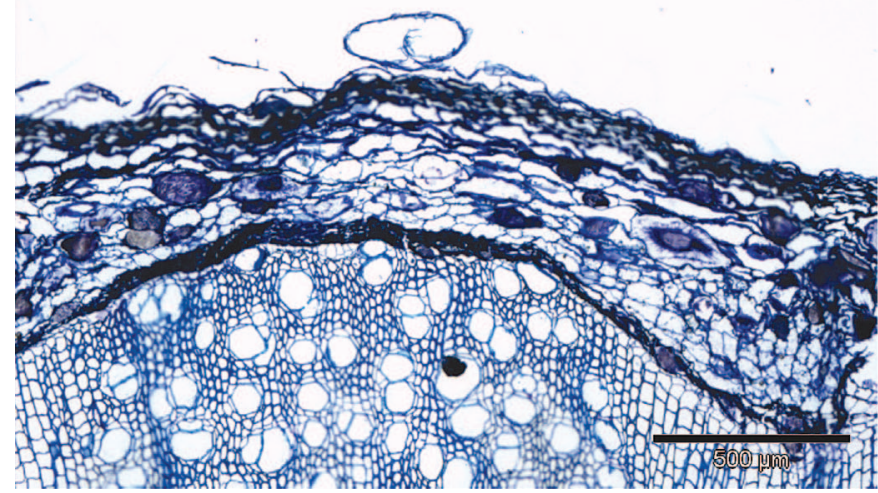

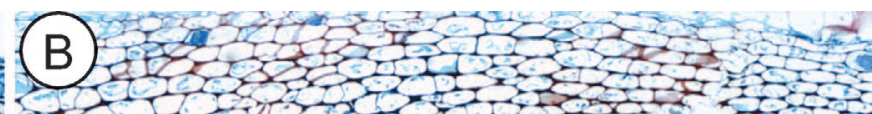
I 35 र

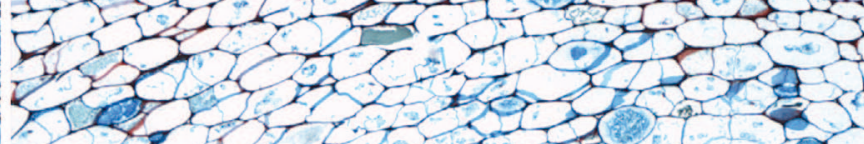

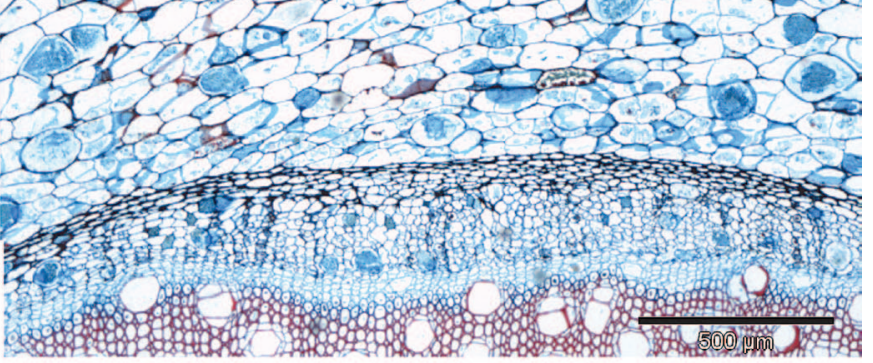
(D) (3) (F)

Fig. 2. Light microscope pictures of transverse bark sections of a species with soft bark (Impatiens niamniamensis), using Carlquist's original paraffin method (A-B), our adjusted method (C-D) and LR White embedding (E-F). A, C, E, Dried stems; B, D, F, fresh stems. A, Secondary phloem collapsed (arrows); B, secondary phloem intact, some damaged cell walls in the collenchyma and parenchyma; $\mathbf{C}$, secondary phloem collapsed (arrows); D, secondary phloem and remaining bark tissues intact; $\mathbf{E}$, severe cell wall collapse in entire bark; $\mathbf{F}$, secondary phloem and remaining bark tissues intact. 


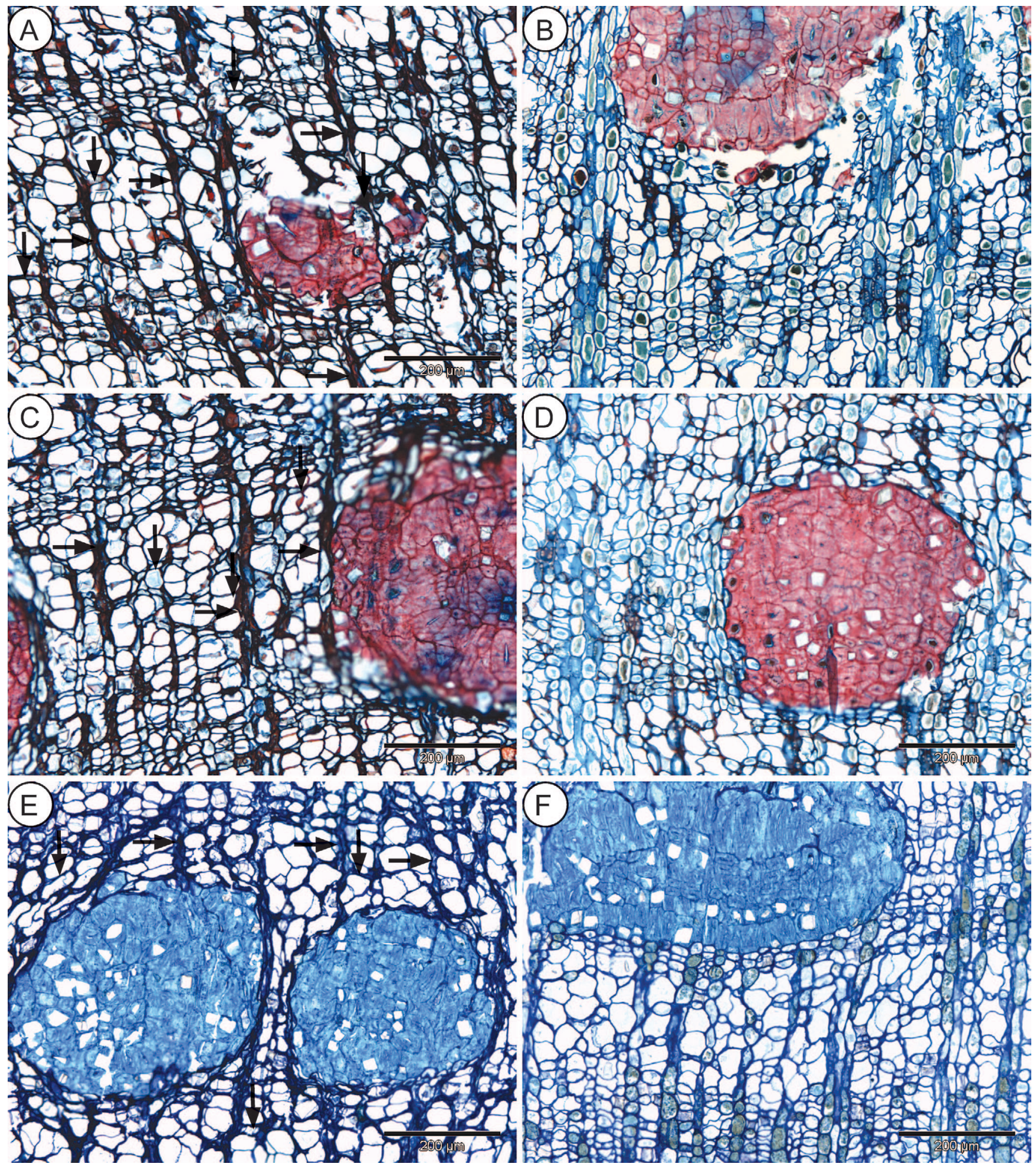

Fig. 3. Light microscope pictures of transverse bark sections of a species with hard bark (Davidia involucrata), using Carlquist's original paraffin method (A-B), our adjusted method (C-D) and LR White embedding (E-F). A, C, E, Dried stems; B, D, F, fresh stems. A, Walls of thin-walled secondary phloem cells are often crushed and torn, especially in the regions near the thick-walled sclereids, collapsed parenchyma cells indicated by arrows (horizontal arrows: ray parenchyma, vertical arrows: axial parenchyma); B, walls of thin-walled secondary phloem cells are frequently
crushed and torn in the regions near the thick-walled sclereids; $\mathbf{C}$, walls of secondary phloem cells sometimes crushed, collapsed parenchyma cells indicated by arrows (horizontal arrows: ray parenchyma, vertical arrows: axial parenchyma); D, secondary phloem intact, rarely crushed; E, walls of secondary phloem cells sometimes crushed, collapsed parenchyma cells indicated by arrows (horizontal arrows: ray parenchyma, vertical arrows: axial parenchyma); $\mathbf{F}$, secondary phloem intact. 
just before sectioning, but also to the longer dehydration and embedding procedures of the paraffin methods. Furthermore, when fresh samples are studied, our improved paraffin-based technique (Figs. 2D, 3D) increases the quality of bark anatomical sections in Impatiens and Davidia, compared to Carlquist's original method (Figs. 2B, 3B). Using our improved method, sectioning is noticeably easier and smoother, especially in species with a mixture of soft and hard bark cells, such as Davidia. With fresh material, the LR White protocol results in comparable (in case of soft bark tissues; Fig. 2F) or even slightly better sections (in case of harder bark tissues; Figs. 3F) than paraffin-based methods (Fig. 2B, D, 3B, D).

Although LR White embedding does not require softening, which leads to a significant reduction of the embedding process time compared to paraffin embedding (1 week vs. 2-3 weeks), and much thinner sections (up to $1-2 \mu \mathrm{m}$ ) are possible, we prefer our adjusted paraffin method to the LR White protocol, because the latter has several major drawbacks compared to the paraffin technique: (1) LR White is much harder and thus more difficult to trim and to section, resulting in smaller-sized samples that are not efficient when the entire radial diameter of mature bark needs to be sectioned; (2) correction of the orientation of the embedded LR White tissue is much more limited during sectioning; (3) serial tangential sectioning of bark is more complicated and much more time-consuming in resin-embedded stems as sections do not stick to each other and may curl strongly; and (4) staining possibilities in LR White are more limited because some specific bark stains cannot be used as they will stain the LR White resin or cannot penetrate the resin.

Bark macerations. - Jeffrey's method (cf. Johansen, 1940) (Fig. 4C, D) is the only maceration method that satisfactorily macerates bark tissue. No obvious difference was noticed between Schmid's improved Jeffrey's method (Schmid, 1982) and Jeffrey's original method. A maceration time of 24 hours is the absolute minimum for Jeffrey's method; tissue samples can be macerated longer if needed. Gifford's and Mahlberg's maceration methods (cf. Ruzin, 1999) are not aggressive enough to macerate the harder tissues, making it impossible to dissect the bark slivers. On the other hand, Franklin's method (Franklin, 1945) (Fig. 4B) is too aggressive, and dramatically damages the most fragile tissues of the phloem, such as sieve elements, while any periderm tissue present remains intact. Macerated tissues stained in $1 \%$ safranin in water have excellent contrast,

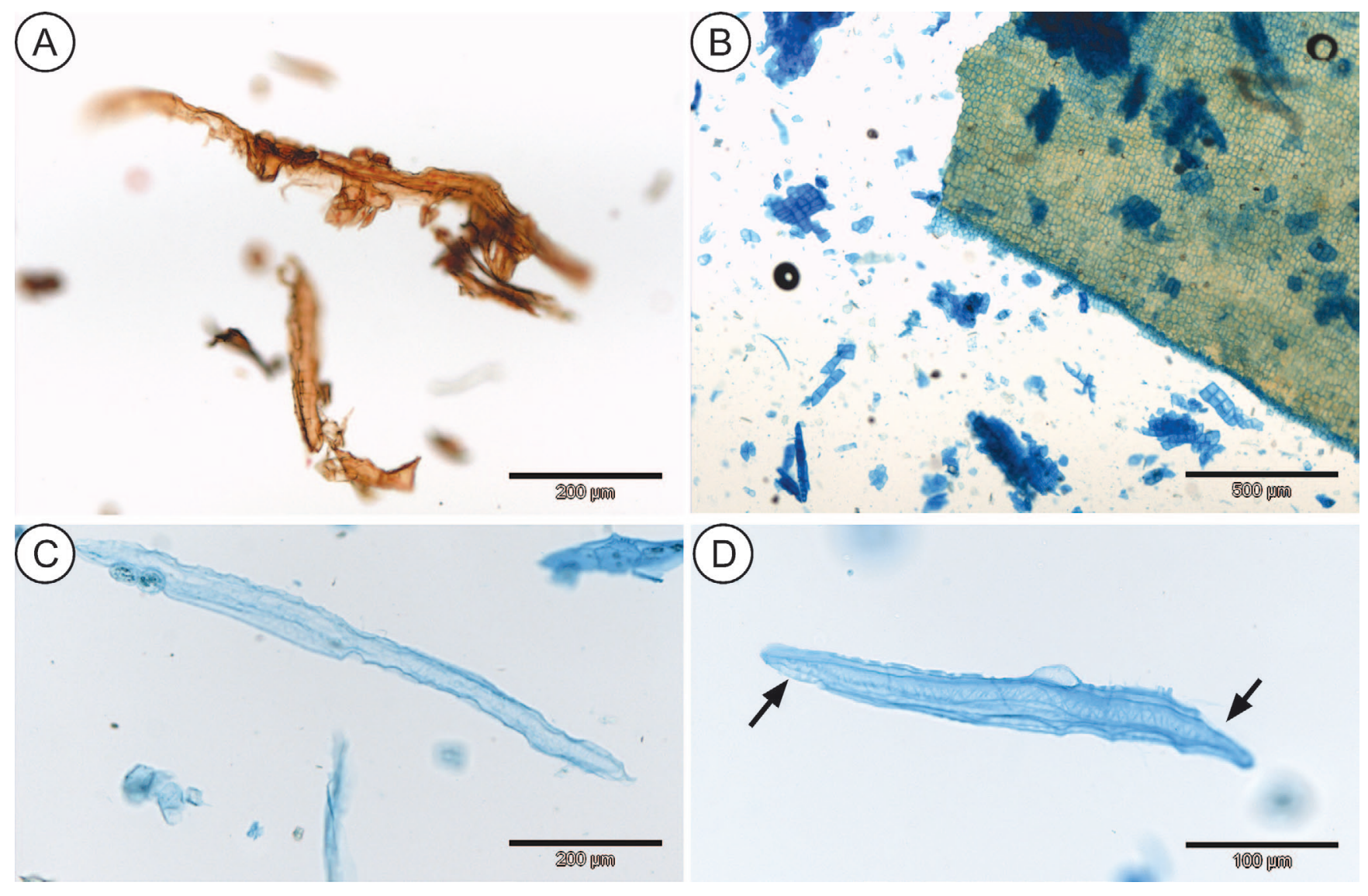

Fig. 4. Light microscope pictures of macerations of Davidia involucrate. A-B, Failed macerations: A, tissue macerated with Jeffrey's method and stained with safranin in alcohol; fragile tissues badly damaged due to dehydration and mounting process; B, tissue macerated in Franklin's maceration mix and stained with astra blue; periderm failed to macerate, sieve elements unrecognizable. C-D, Successful macerations using Jeffrey's method and astra blue stain: C, intact sieve element from dried sample; D, intact sieve element from fresh sample, with clearly visible sieve plates (arrows) and lateral wall sieve areas. 
but require several dozen rinsing steps in water to prevent safranin residues from strongly staining the glycerin-gelatin. These rinsing steps will damage the macerated material. The dehydration steps required for staining in $1 \%$ safranin in $50 \%$ alcohol and the subsequent mounting in Depex severely damage the fragile bark tissues as well (Fig. 4A). Astra blue does not require damaging rinsing steps in water to remove excess stain and generally yields good results, and therefore is preferred. Surprisingly, it is possible to make satisfactory maceration slides using dried bark that is otherwise unsuitable for sectioning, although finding intact cells is somewhat difficult (Fig. 4C). However, the best macerations are those that use recently collected fresh material that has been preserved in alcohol or an appropriate fixative, which have many intact cells showing excellent details, including sieve plates and lateral sieve areas (Figs. 4D).

\section{CONCLUSIONS}

Using our relatively simple adjustments of Carlquist's ethylenediamine method it is possible to improve the quality of bark sections of dried and especially fresh stems collected in the field. We prefer our suggested paraffin protocol over LR White because of the possibility to make more and larger sections in a shorter time frame, and the advantage of having a wider range of applicable stains. Similarly, our modifications to Jeffrey's maceration method make it possible to obtain excellent bark macerations. Based on the bark anatomical literature, we believe that bark anatomy has a great potential as a valuable source of phylogenetically informative characters that should be included in systematic studies. We hope that the present paper will contribute to a revival of bark anatomical research in the systematic community.

\section{LITERATURE CITED}

Archer, R.H. \& Van Wyk, A.E. 1993. Bark structure and intergeneric relationships of some Southern African Cassinoideae (Celastraceae). I.A.W.A. J. 14: 35-53.

Barbosa, A.C.F., Pace, M.R., Witovisk, L. \& Angyalossy, V. 2010. A new method to obtain good anatomical slides of heterogeneous plant parts. I.A.W.A. J. 31: 373-383.

Boura, A. \& De Franceschi, D. 2008. Une méthode simple de collecte de bois et d'écorce pour des études anatomiques. Adansonia, Mém. 30: 7-15.

Burns, W.A. 1978. Thick sections: Techniques and applications. Pp. 141-166 in: Trump, B.F. \& Jones, R.T. (eds.), Diagnosis electron microscopy, vol. 1. New York: Wiley.

Carlquist, S. 1982. The use of ethylenediamine in softening hard plant structures for paraffin sectioning. Stain Technol. 57: 311-317.

Carlquist, S. 1991. Wood and bark anatomy of Ticodendron: Comments on relationships. Ann. Missouri Bot. Gard. 78: 96-104.

Carlquist, S. 1996. Wood, bark, and stem anatomy of Gnetales: A summary. Int. J. Pl. Sci. 157: S58-S76.

Carlquist, S. 1998. Wood and bark anatomy of Caricaceae; correlations with systematics and habit. I.A.W.A. J. 19: 191-206.

Carlquist, S. 2005. Wood and bark anatomy of Muntingiaceae: A phylogenetic comparison within Malvales s.1. Brittonia 57: 59-67.
Castro, M.A., Apóstolo, N.M. \& De Magistris, A.A. 2005. Bark anatomy of Nothofagus species (Nothofagaceae) indigenous to the Andean-Patagonian forest, Argentina. Austral. J. Bot. 53: 69-79.

Cheadle, V.I., Gifford, E.M. \& Esau, K. 1953. A staining combination for phloem and contiguous tissues. Stain Technol. 28: 49-53.

Costa, C.G., Coradin, V.T.R., Czarneski, C.M. \& Pereira, B.A. da S. 1997. Bark anatomy of arborescent Leguminosae of cerrado and gallery forest of Central Brazil. I.A.W.A. J. 18: 385-399.

De Magistris, A.A. \& Castro, M.A. 2001. Bark anatomy of southern South American Cupressaceae. I.A.W.A. J. 22: 367-383.

Echols, R.M. 1955. Aluminum foil boats for paraffin casting. Stain Technol. 30: 65-67.

Esau, K. 1969. The phloem. Band 5, Teil 2, Histologie of: Ozenda, P., Wulff, H.D. \& Zimmermann, W. (eds.), Handbuch der Pflanzenanatomie. Berlin: Borntraeger.

Esau, K. \& Cheadle, V.I. 1984. Anatomy of the secondary phloem in Winteraceae. I.A.W.A. Bull., n.s., 5: 13-43.

Forster, T., Schweingruber, F.H. \& Denneler, B. 2000. Increment puncher: A tool for extracting small cores of wood and bark from living trees. I.A.W.A. J. 21: 169-180.

Franklin, G.L. 1945. Preparation of thin sections of synthetic resins and wood-resin composites, and a new macerating method for wood. Nature 151: 51.

Hamann, T.D. 2009. Bark anatomy of Cornales and Ericales. Master thesis, Universiteit Leiden, Leiden, The Netherlands.

IAWA Committee. 1989. IAWA list of microscopic features for hardwood identification. I.A.W.A. Bull., n.s., 10: 221-332.

Jansen, S., Baas, P., Gasson, P., Lens, F. \& Smets, E. 2004. Variation in xylem structure from tropics to tundra: Evidence from vestured pits. Proc. Natl. Acad. Sci. U.S.A. 101: 8833-8837.

Johansen, D.A. 1940. Plant microtechnique. New York: McGraw-Hill.

Junikka, L. 1994. Survey of English macroscopic bark terminology. I.A.W.A. J. 15: 3-45.

Junikka, L. \& Koek-Noorman, J. 2007. Anatomical structure of barks in Neotropical genera of Annonaceae. Ann. Bot. Fenn. 44A: 79-132.

Keating, R.C. 1996. Anther investigations: A review of methods. Pp. 255-271 in: D'Arcy, W.G. \& Keating, R.C. (eds.), The anther: Form, function and phylogeny. New York: Cambridge University Press.

Lens, F., Dressler, S., Jansen, S., Van Evelghem, L. \& Smets, E. 2005. Relationships within balsaminoid Ericales: A wood anatomical approach. Amer. J. Bot. 92: 941-953.

Lens, F., Kårehed, J., Baas, P., Jansen, S., Rabaey, D., Huysmans, S., Hamann, T. \& Smets, E. 2008. The wood anatomy of the polyphyletic Icacinaceae s.l., and their relationships within asterids. Taxon 57: 525-552.

Lens, F., Schönenberger, J., Baas, P., Jansen, S. \& Smets, E. 2007. The role of wood anatomy in phylogeny reconstruction of Ericales. Cladistics 23: 229-254.

Ley-Yadun, S. 1991. Terminology used in bark anatomy: Additions and comments. I.A.W.A. Bull., n.s., 12: 207-209.

Liu, D. \& Gao, X. 1993. Comparative anatomy of the secondary phloem of ten species of Rosaceae. I.A.W.A. J. 14: 289-298.

Melzer, S., Lens, F., Gennen, J., Vanneste, S., Rhode, A. \& Beeckman, T. 2008. Flowering-time genes modulate meristem determinacy and growth form in Arabidopsis. Nat. Genet. 40: 1489-1492.

Mercer, E.H. 1963. A scheme for section staining in electron microscopy. J. Roy. Microscop. Soc. London 81: 179-186.

Metcalfe, C.R. \& Chalk, L. 1950a. Anatomy of the dicotyledons, vol. 1. London: Oxford University Press.

Metcalfe, C.R. \& Chalk, L. 1950b. Anatomy of the Dicotyledons, vol. 2. London: Oxford University Press.

Olson, M.E. 2005. Wood, bark, and pith anatomy in Pittocaulon (Senecio, Asteraceae): Water storage and systematics. J. Torrey Bot. Soc. 132: 173-186. 
Oskolski, A.A., Kotina, E.L., Fomichev, I.V., Tronchet, F. \& Lowry, P.P., II. 2007. Systematic implications of wood and bark anatomy in the Pacific Island genus Meryta (Araliaceae). Bot. J. Linn. Soc. 153: 363-379.

Oskolski, A.A., Rossouw, A.S. \& Van Wyk, B.E. 2010. Wood and bark anatomy of Steganotaenia and Polemanniopsis (tribe Steganotaenieae, Apiaceae) with notes on phylogenetic implications. Bot. J. Linn. Soc. 163: 55-69.

Pappas, P.W. 1971. The use of a chrome alum-gelatin (subbing) solution as a general adhesive for paraffin sections. Stain Technol. 46: $121-124$.

Richter, H.G. 1981. Anatomie des sekundären Xylems und der Rinde der Lauraceae. Sonderb. Naturwiss. Vereins Hamburg 5: 26.

Riopel, J.L. 1962. Carbowax for embedding and serial sectioning of botanical material. Stain Technol. 37: 357-362.

Rossi, S., Anfodillo, T. \& Menardi, R. 2006. Trephor: A new tool for sampling microcores from tree stems. I.A.W.A. J. 27: 89-97.
Roth, I. 1981. Structural patterns of tropical barks. Band 9, Teil 3, Spezieller Teil of: Braun, H.J., Carlquist, S., Ozenda, P. \& Roth, I. (eds.), Handbuch der Pflanzenanatomie. Berlin: Borntraeger.

Ruzin, S.E. 1999. Plant microtechnique and microscopy. New York: Oxford University Press.

Sass, J.E. 1968. Botanical microtechnique. Ames: The Iowa State University Press.

Schmid, R. 1982. Sonication and other improvements on Jeffrey's technique for macerating wood. Stain Technol. 57: 293-299.

Schweingruber, F.H. 2006. Anatomical characteristics and ecological trends in the xylem and phloem of Brassicaceae and Resedaceae. I.A.W.A. J. 27: 419-442.

Trockenbrodt, M. 1990. Survey and discussion of the terminology used in bark anatomy. I.A.W.A. Bull., n.s., 11: 141-166.

Zahur, M.S. 1959. Comparative study of secondary phloem of 423 species of woody dicotyledons belonging to 85 families. Mem. Cornell Univ. Agric. Exp. Sta. 358: 1-160. 